\title{
Traumatic Brain Injury in the Elderly: Is it as Bad as we Think?
}

\author{
Calvin H. K. Mak • Stephen K. H. Wong • \\ George K. Wong • Stephanie Ng • Kevin K. W. Wang • \\ Ping Kuen Lam • Wai Sang Poon
}

Published online: 6 July 2012

(C) The Author(s) 2012. This article is published with open access at Springerlink.com

\begin{abstract}
Traumatic brain injury in elderly patients is a neglected global disease burden. The main cause is fall, followed by motor vehicle accidents. This review article summarizes different aspects of geriatric traumatic brain injury, including epidemiology, pathology, and effects of comorbidities and pre-injury medications such as antiplatelets and anticoagulants. Functional outcome with or without surgical intervention, cognitive outcome, and psychiatric complications are discussed. Animal models are also reviewed in attempt to explain the relationship of aging and outcome, together with advances in stem cell research. Though elderly people in general did fare worse after traumatic brain injury, certain "younger elderly" people, aged 6575 years, could have a comparable outcome to younger adults after minor to moderate head injury.
\end{abstract}

C. H. K. Mak · S. K. H. Wong $\cdot$ G. K. Wong $\cdot$ S. Ng $•$

W. S. Poon $(\bowtie)$

Division of Neurosurgery, Department of Surgery,

The Chinese University of Hong Kong, Prince of Wales Hospital,

Shatin, Hong Kong

e-mail:wpoon@surgery.cuhk.edu.hk

K. K. W. Wang

Division of Neurosurgery, Department of Surgery,

The Chinese University of Hong Kong, Prince of Wales Hospital, Shatin, Hong Kong

K. K. W. Wang

Center for Neuroproteomics and Biomarkers Research,

The Department of Psychiatry and Neuroscience,

McKnight Brain Institute, University of Florida,

Gainesville, FL 32611, USA

P. K. Lam

Chow Tai Fook-Cheung Yu Tung Surgical Stem Cell Research

Center, Department of Surgery,

The Chinese University of Hong Kong, Prince of Wales Hospital,

Shatin, Hong Kong
Keywords Traumatic brain injury · Elderly $\cdot$ Geriatric . Aging $\cdot$ Review $\cdot$ Animal studies $\cdot$ Stem cell $\cdot$ Drugs . Anticoagulation · Antiplatelet · Warfarin · Aspirin . Clopidogrel $\cdot$ Epidemiology $\cdot$ Outcome $\cdot$ Cognitive Craniotomy $\cdot$ Decompressive craniectomy

\section{Introduction}

According to the World Health Organization, traumatic brain injury (TBI) will lead as the major cause of death and disability by the year 2020. It is estimated that 10 million people are affected annually by TBI [1]. Often neglected, elderly TBI patients are going to be an increasing burden to the society with the worldwide aging population. Peschman et al. [2] showed that age alone is associated with increased odds of being admitted to the hospital after head injury.

In the United States, there are 1.4 million cases of TBI per year, causing over 90,000 cases of permanent disability and 50,000 deaths. Specifically, among the elderly, there are 155,000 cases of TBI annually in the United States leading to 12,000 deaths [3]. There is also an increasing incidence of patients with TBI being discharged to the elderly home over the recent years [4].

Elderly patients suffering from head injury were traditionally thought to have an inferior outcome. They were more likely to go to inpatient rehabilitation or long-term care facilities, or died compared to young and middle-aged patients [5]. Elderly TBI patients also bear higher cost during hospital stay in cost-analysis models [6].

Thus, elderly TBI patients tend to be treated less aggressively. In a retrospective multicenter study in Scotland, older patients with acute intracranial hematomas were less likely to be transferred for specialist neurosurgical care than 
younger patients with similar severities of injuries, extracranial injuries, and physiological status at presentation, irrespective of associated medical morbidities [7].

These concepts are recently being challenged as clinicians observe that with adequate resources, timely and appropriate surgical intervention, neurointensive care, and aggressive neurorehabilitation, both functional and cognitive outcome of elderly TBI patients may be as good as the younger counterparts. We thus reviewed the current evidence in the literature regarding factors affecting outcome after geriatric TBI and aimed to define the role of aggressive neurosurgical management in geriatric TBI.

\section{Methods}

Studies included in the present article were identified by searching through PubMed and MEDLINE using keywords: [traumatic brain injury OR head injury] AND [elderly OR geriatric] AND [epidemiology OR outcome]. Non-English articles were excluded.

\section{Epidemiology}

Trauma literature usually defines "elderly" as more than 65 years of age, which is used in this review unless otherwise specified $[6,7,8 \bullet \bullet, 9 \bullet, 10,11 \bullet \bullet, 12-14,15 \bullet \cdot, 16-24]$.

Incidence of elderly TBI has doubled in the past 18 years that the increase in elderly TBI is greatest for individuals aged $83-90$ years [15••]. Fall at level ground is the leading cause of TBI in elderly patients, followed by motor vehicle accidents (MVA) [5, 19, 25-27]. It may be postulated that the increase in elderly TBI can be explained by an increase in life expectancy and advances in health care; while physiologically, elderly people are more susceptible to fall.

Fall is a major disease burden worldwide. In a retrospective cohort in India, $40 \%$ of the elderly patients who fell injured their heads, where half of them presented with severe head injury (Glasgow Coma Scale [GCS]<9) [28]. In the United States (Oklahoma), the rate of elderly fall causing TBI showed $120 \%$ increase over the last decade [18].

Hong Kong, one of the busiest cities in Asia, has a low MVA-related death rate $(2.4$ per 100,000$)$, which is $25 \%$ of Australian and $15 \%$ of U.S. rates. In Hong Kong, $37 \%$ of MVA-related death was among elderly people over 60 years old. Over $80 \%$ of the deceased across all age groups sustained head injury [29].

\section{Pathology}

Acute subdural hematoma was the commonest pathology for elderly TBI [30], which corresponds with a coroner's report that subdural hematoma was the commonest lesion of the deceased elderly persons with head injuries [12].

\section{Comorbidities}

Medical comorbidities are found in $40 \%$ of the elderly population [31]. They are more likely to suffer from cardiovascular diseases, and may lead to the overwhelming prescription of anticoagulation and antiplatelet agents, which are discussed in details below.

Anticoagulants

Almost one fifth of elderly patients older than 65 years old admitted to an American level 1 trauma center with head injury were on warfarin, reflecting the importance of impact of warfarin on management and outcome of head injuries [14].

Warfarin consumption is independently associated with higher mortality among a cohort of 384 TBI patients over 55 years old [32]. Those on warfarin with minor head injuries (GCS $\geq 13)$ are 2.7 times more likely to suffer from intracranial hemorrhage (ICH), and traumatic ICH was associated with supratherapeutic international normalized ratio (INR) [33].

In a retrospective analysis of 1493 patients with head injury, INR over 4.0 and age over 70 years were associated with higher mortality. Warfarin carries a sixfold increase in TBI mortality [34]. Pieracci et al. [14] compared warfarin users with mean INR 3.3 versus those with suboptimal level, with the former group having a lower GCS score on presentation and higher mortality after head injury. Karni et al. [35] reported similarly that the 30-day mortality was $50 \%$ in warfarinized elderly patients with mean INR 3.0, compared to the mortality of $20 \%$ in nonwarfarinized counterparts. With a mean initial INR of 4.0, warfarin can be even more lethal in elderly TBI, with over $80 \%$ mortality in those with initial minor head injury [36].

Delayed ICH with oral anticoagulant and head injury also were reported among elderly patients [37]. However, routine follow scan in negative first computer tomography (CT) scan of brain in warfarinized patients has a very low yield of $1 \%$ delayed ICH after head injury $[22,38]$.

New direct coagulation factor inhibitors, such as dabigatran, have suggested superior stroke and systemic embolism prevention with less drug-drug interactions. However, there is still no specific reversal agent and routine laboratory essay to measure anticoagulation level in patients with traumatic ICH [39].

Antiplatelets

Pre-injury antiplatelet agents were associated with three times higher mortality among patients over 50 years old, 
where it was due to a functional rather than quantitative deficiency of platelets [26].

Intracranial bleeding progressed in $10 \%$ of elderly TBI patients on clopidogrel. They were three times more likely to be discharged to long-term inpatient facilities and 14 times higher mortality rate as compared with those not on antiplatelets [40].

However, platelet transfusion was shown not beneficial in terms of mortality among patients older than 50 years old with pre-injury antiplatelets who suffered from TBI with ICH [41]. Routine platelet transfusion may even be harmful. Washington et al. [42••] showed that in patients who were on antiplatelets and sustained minor head injury, where the first CT scan showed intracranial hematoma that did not require immediate operative treatment, platelet transfusion had a higher rate of medical complications, including death due to cardiac causes. There was no difference in terms of neurological decline between the transfused and nontransfused group. Fortuna et al. [43] similarly reported higher mortality for patients with pre-injury antiplatelets who received platelet transfusion therapy compared with those who were not transfused. Utilization of commercially available aspirin response test could assess the effect of existing aspirin therapy in TBI patients, thus possibly avoiding unnecessary futile platelet transfusion [44].

\section{$\beta$-Blockers}

The relationship with use of $\beta$-blockers and outcome in TBI patients is complex. On one hand, some retrospective data suggest that $\beta$-blocker users have a lower mortality in elderly patients suffering from severe blunt head injury, hypothesizing that $\beta$-blockade may result in attenuation of intracerebral post-traumatic catecholamine-induced vasospasm, decreasing potential for local ischemia [45]. However, in those with severe systemic injuries, $\beta$-blockers may mask the systemic response to trauma, leading to higher mortality [21].

\section{Statins}

Preinjury statin use in elderly TBI patients is associated with reduced risk of death and greater likelihood of achieving a good recovery at 12 months postinjury, possibly related to anti-inflammatory and immunomodulatory effects of statins [23].

\section{Functional Outcome}

The overall mortality for elderly TBI patients older than 65 years old was $14 \%-55 \%[11 \bullet, 17-19,24,25,46]$, and was affected mainly by GCS on admission, followed by age.

GCS on admission, described by Jennett et al. in 1976 [47], had long been known to predict outcome. In a large multicenter epidemiologic study of TBI in China, minor head injury patients (GCS 13-15) had over $90 \%$ survival, where less than $20 \%$ achieved good outcome in severe head injury patients (GCS 3-8) [46]. Several studies also showed severe head injury among elderly led to high mortality, ranging from $68 \%-92.5 \%$, and less than one fifth achieved good outcome at 6 months (Table 1).

Despite the fact that older patients tend to suffer from less severe injuries, elderly age is associated with higher mortality and worse functional status at discharge $[3,15 \bullet \cdot, 24,25,50]$. Elderly patients over 70 years old sustaining severe head injury had $80 \%$ mortality and no one made good recovery at 6 months. The outcome was similar in the same center over 10 year's time. However, the sample size was small [30].

Another multicenter study in Japan reported that good recovery was only achieved in $10 \%$ in those victims over 50 years old, with over $60 \%$ mortality, and $10 \%$ remained in vegetative state. The factor of neurosurgical intervention was not included [51].

Recent large-scale studies suggested that the outcome of elderly TBI is encouraging. Elderly patients over 65 years old had a survival rate of over $80 \%$ at a retrospective cohort data at a level II trauma center in Florida from 2005 to 2008 $[11 \bullet \cdot]$. In a large-scale multicenter epidemiologic study of TBI in Eastern China conducted in 2004, around $60 \%$ of TBI patients over 65 years old enjoyed good recovery [46].

Increasing number of elderly individuals are surviving moderate to severe TBI over the past two decades as reported by Ramanathan et al. [15], similar to findings using statewide data collected in Oklahoma [18]. When adjusted for sex, year of TBI, and TBI severity, elderly patients showed similar risk of death following head injury as younger patients [17]. In a 10-year Singapore review, though significantly less than the younger victims, $36 \%$ of elderly with initial GCS over 8 managed to attain good outcome [19].

Inpatient rehabilitation was shown to improve outcome at 6 months even in certain deeply comatose elderly head injury patients, as measured by significant gains on the modified Barthel Index after rehabilitation [52].

\section{"Younger" Elderly}

Neurosurgical unit care, especially in intensive care unit, significantly reduced mortality in those with severe head injury between 65 and 70 years old. Mortality in severe TBI elderly with GCS $6-8$ was $47 \%$ and $56 \%$ in patients of 65-70 years old and 70-75 years old respectively, which is much better than the overall mortality of $78.5 \%$ in the overall elderly group $[8 \bullet \bullet$. 
Table 1 Outcome of elderly traumatic brain injury with severe head injury (GCS 3-8 on admission)
*Good outcome as defined by Glasgow Outcome Score 4-5 GCS Glasgow Coma Scale

\begin{tabular}{|c|c|c|c|c|c|c|}
\hline Study & Year & $\begin{array}{l}\text { Period of data } \\
\text { collection }\end{array}$ & $\begin{array}{l}\text { Age, } \\
y\end{array}$ & $\begin{array}{l}\text { Patients, } \\
n\end{array}$ & $\begin{array}{l}\text { Mortality, } \\
\%\end{array}$ & $\begin{array}{l}\text { Good outcome at } \\
6 \text { months*, } \%\end{array}$ \\
\hline Kilaru et al. [48] & 1996 & 1990-1995 & $65+$ & 40 & 68 & 7.5 \\
\hline Hukkloven et al. [49] & 2003 & 1991-1995 & $65+$ & 101 & 72 & 15 \\
\hline Ushewokunze et al. [30] & 2004 & $1990-2000$ & $70+$ & 71 & 80 & 1 \\
\hline Gan et al. [19] & 2004 & 1999-2001 & $64+$ & 36 & 72.2 & 16.7 \\
\hline \multirow[t]{5}{*}{ Patel et al. $[8 \bullet \bullet]$} & 2010 & 1996-2004 & $65+$ & 669 & 80.7 & \\
\hline & & & $65-70$ & 137 & 71.5 & \\
\hline & & & $70-75$ & 147 & 74.8 & \\
\hline & & & $75-80$ & 160 & 85 & \\
\hline & & & $80+$ & 225 & 87 & \\
\hline \multirow[t]{2}{*}{ Bouras et al. [16] } & 2007 & $1998-2005$ & $65-74$ & 48 & 79.2 & \\
\hline & & & $75+$ & 67 & 92.5 & \\
\hline
\end{tabular}

This is similar with the data from the Greek group [16], that there is a trend of improved survival of the "younger elderly" (65-75 years old) with ICU treatment. Furthermore, the "younger elderly" had a comparable survival with the younger counterparts who are less than 65 years old after surgical intervention in patients with GCS of 8 or higher.

\section{Surgical Intervention}

Overall survival and good recovery following craniotomy in elderly head injury was $30 \%-77 \%$, with GCS over 8 upon admission showing better outcome [7, 20, 31, 53••, 54]. Volume of traumatic ICH greater than $50 \mathrm{ml}$ was associated with poor 1-year outcome [25]. A cohort showed that, with appropriate postoperative medical attention, selected patients older than 80 years old with single traumatic hematoma undergoing craniotomy can similarly return to preinjury functional conditions as their younger counterparts [55•].

On the other hand, decompressive craniectomy does not show significant benefit in older patients after failing maximal medical treatment [10]. At 1 year after decompressive craniectomy, $80 \%$ of elderly patients with severe TBI had poor outcome. Most patients who died had a controlled intracranial pressure (ICP) after surgery and no surgeryrelated complications. The brain's greater exposure to minor repetitive insults as age increases, together with the presence of systemic comorbidities such as vasculopathies and neuropathies, likely contributes to the brain's reduced capacity for recovery and may therefore have an inferior impact on prognosis [9•].

\section{Cognitive Outcome}

There is some evidence to suggest that moderate to severe head injury can predispose to development of cognitive decline and even Alzheimer's disease decades afterwards
[56-58]. A 9-year population-based study of elderly patients also showed fall-related TBI predicts earlier onset of dementia and the effect is especially high amongst patients who carry the apolipoprotein E $\varepsilon 4$ allele [59]. However, it is not reproducible in other studies, and failed to find an association between history of TBI and dementia [60]. Elderly patients are also more prone to cognitive dysfunction after TBI [61].

Repetitive minor blunt head injuries can cause chronic traumatic encephalopathy at a later stage of life, characterized with memory disturbances, behavioral and personality changes, Parkinsonism, and speech and gait abnormalities. Pathologically, there are extensive tau-immunoreactive neurofibrillary tangles throughout the brain in relative absence of $\beta$-amyloid deposits. There are reports that repetitive head trauma also can be associated with development of motor neuron disease $[62,63]$.

According to a systemic review, prevalence of depression in community-residing elderly adults ranges from $1.8 \%$ $8.9 \%$ in the community and $10 \%-25 \%$ in medical and long-term care settings. In the general population with TBI, prevalence rates of depression range from $10 \%-42 \%$, with older age being a significant factor [13, 64]. Imaging study based on magnetic resonance imaging (MRI) suggested the possible role of frontotemporal lobe and basal ganglia pathology in depression after TBI [65]. TBI may increase the risk of disinhibition in elderly patients with dementia [66].

\section{Animal and Experimental Studies}

Researchers have been trying to determine why and how age plays a role in outcome of TBI. Onyszchuk and colleagues $[67,68]$ studied the effect of trauma to the brain among mice. Aged mice performed worse in general compared with the adult group. The aged group showed slower resolution in brain edema in MRI. Immunostaining showed greater 
degree in opening in blood-brain barriers and higher degree in neurodegeneration in aged mice. The effects not only affected the acute phase, but also were present 2 months after injury. A similar study comparing both the aged and younger mice was published by Sandhir et al. [69], who focused on the age-dependent response of CCAAT/enhancer binding proteins (CEBP). The aged brain showed a significant increase in both the CEBP $\beta$ - and $\delta$ - protein, which are responsible for glia activation in neurotoxic events and development of Alzheimer's disease.

There have been recent advances in genetic studies related to TBI. Colak et al. [70] identified that several genes were upregulated in injured brains (eg, C1q12, Cbnl, $5 \mathrm{dc} 1 \mathrm{Bdnf}$, MMP9, and Cd47), which are responsible for neuroprotection and nerve repair. Mehan et al. [71] showed that a series of protein isoforms was induced only in juvenile brains but not in the elder brains among mice.

Targeted therapies toward these particular genes have been studied, and age also serves as an important factor in the response of the brain toward the treatment modalities. Nicotinamide was found to be only effective in younger mice to improve functional recovery in TBI [72]. Nogo-A/ $\mathrm{B}$, myelin-derived inhibitors to axonal outgrowth, were genetically modified to be negative in experimental mice. The younger mice expectedly had a better outcome, yet showed contrary results in the aged group [73].

Preclinical trials focused on stem cell therapy to traumatic nervous tissue injury are promising, as summarized by Harting and colleagues [74]. Embryonic stem cells (ESCs) derived from the inner mass of blastocyst are capable of producing all tissues of the body [75]. Neural stem cells (NSCs) isolated from subventricular zone and dentate gyrus of hippocampus are multipotent cells with the potential to differentiate into neurons, oligodendrocytes, and astrocytes [76]. Clinical applications of ESCs and NSCs are hindered by ethical controversies, concern of tumor formation, and limited availability respectively. Mesenchymal stem cells (MSCs) can be isolated from bone marrow and adipose tissue, among other sources, and rapidly expanded in vitro without losing their general multipotentiality [77]. MSCs also can differentiate into specific cell lineages under appropriate microenvironment. The brain itself has a limited capacity for self-repair. Preclinical studies have demonstrated that MSCs can facilitate the replacement of injured or nonfunctioning cells and improve the functional recovery after TBI [78-80], although the underlying mechanism remains to be defined. Apart from engraftment and transdifferentiation into neurons and astrocytes or fusion with the host cells, MSCs may stimulate neurogenesis, gliagenesis, and synaptogensis via secretion of neuroprotective/trophic factors as well as modulation of microenvironment inflammatory and systemic immunologic responses [81, 82]. TBI elicits a cascade of pathophysiologic processes leading to neuronal damage. Conventional pharmacologic agents usually target only a single pathway, whereas stem cell-based therapies can execute multiple mechanisms and thus give rise to the hope that MSCs may be able to reverse cellular/subcellular cascade underlying brain damage following TBI. Intravenous and intra-arterial injections are most commonly routes for the administration of MSCs in clinical trials. To date, no adverse clinical complication caused by infusion of expanded autologous MSCs for neurological diseases has been reported [83, 84]. However, few infused MSCs reach the injured lesion of the brain because of the pulmonary firstpass effect [85]. The average diameter of MSCs is smaller than that of pulmonary artery. A recent study demonstrated that topically applied MSCs can migrate to the injured parenchymal tissue in the models of TBI (Fig. 1) [86], and ischemia-reperfusion injury in other somatic organs [87•]. Topical application can offer a direct delivery of millions of MSCs to the brain. Clinical efficacy and feasibility of cellbased therapies for TBI require further investigation in

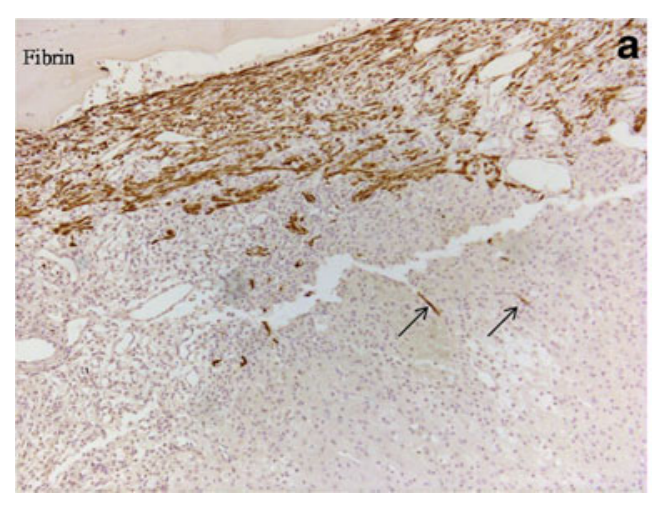

Fig. 1 Topical application of mesenchymal stem cells (MSCs) as potential treatment following severe traumatic brain injury (TBI) in rats. MSCs derived from transgenic Sprague-Dawley (SD) rat with green fluorescent protein (GFP) and a thin layer of fibrin were topically applied on the surface of brain with TBI. a

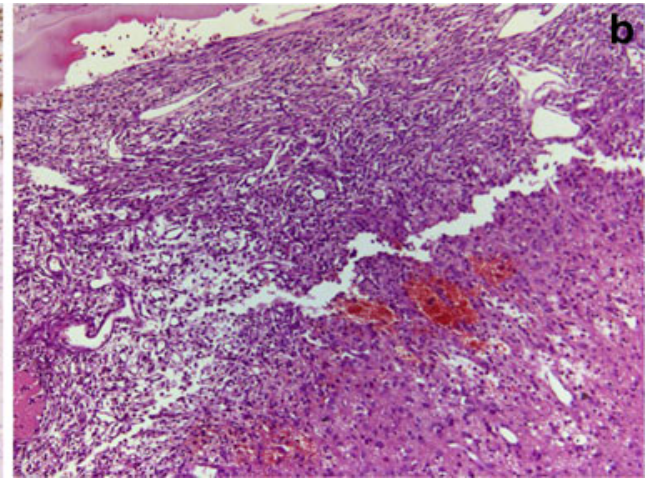

Immunochemistry staining using anti-GFP (IHC x 100; brown) showed the migration of GFP-MSCs (arrows) into parenchymal brain tissue 3 days after topical MSC application. b $\mathrm{H} \& \mathrm{E}$ counter-staining (x 100). IHC immunohistochemical staining; $H$ $\& E$ hematoxylin and eosin 
regard to cell types, cell dosage, routes of administration, and transplantation window.

\section{Conclusions}

Elderly TBI has been and will be an important burden to the society with longer life expectancy and an aging population, with fall being the commonest cause. Increasing use of antiplatelet and anticoagulation medication is going to further complicate the condition. Outcome following TBI in "younger elderly" (ie, those less than 75 years old) can be comparable with younger adults with acceptable outcome. With good case selection of minor to moderate head injury in those relatively younger elderly victims, surgical treatment should not be withheld, and traumatic hematoma evacuation may be beneficial among elderly as opposed to traditional thoughts. Current literature lack dedicated studies to this particular group of patients with less severe head injuries. Animal and laboratory studies showed promising explanation of underlying mechanisms of elderly TBI and development of novel treatment.

Disclosures No potential conflicts of interest relevant to this article were reported.

Open Access This article is distributed under the terms of the Creative Commons Attribution License which permits any use, distribution, and reproduction in any medium, provided the original author(s) and the source are credited.

\section{References}

Papers of particular interest, published recently, have been highlighted as:

- Of importance

.. Of major importance

1. Hyder AA, Wunderlich CA, Puvanachandra P, et al. The impact of traumatic brain injuries: a global perspective. NeuroRehabilitation. 2007;22(5):341-53.

2. Peschman J, Neideen T, Brasel K. The impact of discharging minimally injured trauma patient: does age play a role in trauma admission? J Trauma. 2011;70(6):1331-6.

3. Richmond R, Aldaghlas TA, Burke C, et al. Age: is it all in the head? Factors influencing mortality in elderly patients with head injuries. J Trauma. 2011;71(1):E8-E11.

4. Karon SL, Lazarus JAC, Holman L. Challenges and approaches to the identification of traumatic brain injury among nursing home residents. J Head Trauma Rehabil. 2007;22(6):350-9.

5. LeBlanc J, de Guise E, Gosselin N, et al. Comparison of functional outcome following acute care in young, middle-aged and elderly patients with traumatic brain injury. Brain Inj. 2006;20(8):779-90.
6. Chan LY, Moran JL, Clarke C, et al. Mortality and cost outcomes of elderly trauma patients admitted to intensive care and the general wards of an Australian tertiary referral hospital. Anaesth Intensive Care. 2009;37(5):773-83.

7. Munro PT, Smith RD, Parke TR. Effect of patients' age on management of acute intracranial haematoma: prospective national study. BMJ. 2002;325(7371):1001.

8. •• Patel HC, Bouamra O, Woodford M, et al. Clinical article: mortality associated with severe head injury in the elderly. Acta Neurochir (Wien). 2010;152(8):1353-7. discussion 7. This review article showed that elderly persons below 75 years old and presenting GCS 6-8 may benefit from more aggressive treatment for TBI..

9. - De Bonis P, Pompucci A, Mangiola A, et al. Decompressive craniectomy for elderly patients with traumatic brain injury: it's probably not worth the while. J Neurotrauma. 2011;28(10):2043-8. For treatment of refractory intracranial hypertension after brain injury, decompressive craniectomy is unlikely beneficial among elderly, resulting in bad outcome in most cases.

10. Pompucci A, De Bonis P, Pettorini B, et al. Decompressive craniectomy for traumatic brain injury: patient age and outcome. $\mathrm{J}$ Neurotrauma. 2007;24(7):1182-8.

11. •- Bhullar IS, Roberts EE, Brown L, et al. The effect of age on blunt traumatic brain-injured patients. Am Surg. 2010;76(9):9668. This retrospective review on 2369 patients with blunt head injury showed that patients older than 80 years old had similar outcome in terms of mortality compared to the younger counterparts with similar GCS and Injury Severity Score on admission.

12. Chisholm KM, Harruff RC. Elderly deaths due to ground-level falls. Am J Forensic Med Pathol. 2010;31(4):350-4.

13. Menzel JC. Depression in the elderly after traumatic brain injury: a systematic review. Brain Inj. 2008;22(5):375-80.

14. Pieracci FM, Eachempati SR, Shou J, et al. Degree of anticoagulation, but not warfarin use itself, predicts adverse outcomes after traumatic brain injury in elderly trauma patients. J Trauma. 2007;63(3):525-30.

15. • Ramanathan DM, McWilliams N, Schatz P, et al. Epidemiological Shifts in Elderly TBI: 18-Year Trends in Pennsylvania. J Neurotrauma. 2011. This large-scale retrospective study showed a decrease of mortality rate over time, indicating more elderly patients are surviving moderate to severe TBI.

16. Bouras T, Stranjalis G, Korfias S, et al. Head injury mortality in a geriatric population: differentiating an "edge" age group with better potential for benefit than older poor-prognosis patients. J Neurotrauma. 2007;24(8):1355-61.

17. Flaada JT, Leibson CL, Mandrekar JN, et al. Relative risk of mortality after traumatic brain injury: a population-based study of the role of age and injury severity. J Neurotrauma. 2007;24 (3):435-45.

18. Fletcher AE, Khalid S, Mallonee S. The epidemiology of severe traumatic brain injury among persons 65 years of age and older in Oklahoma, 1992-2003. Brain Inj. 2007;21(7):691-9.

19. Gan BK, Lim JHG, Ng IHB. Outcome of moderate and severe traumatic brain injury amongst the elderly in Singapore. Ann Acad Med Singap. 2004;33(1):63-7.

20. Mitra B, Cameron PA, Gabbe BJ, et al. Management and hospital outcome of the severely head injured elderly patient. ANZ J Surg. 2008;78(7):588-92.

21. Neideen T, Lam M, Brasel KJ. Preinjury beta blockers are associated with increased mortality in geriatric trauma patients. J Trauma. 2008;65(5):1016-20.

22. Reynolds FD, Dietz PA, Higgins D, et al. Time to deterioration of the elderly, anticoagulated, minor head injury patient who presents without evidence of neurologic abnormality. J Trauma. 2003;54(3):492-6.

23. Schneider EB, Efron DT, MacKenzie EJ, et al. Premorbid statin use is associated with improved survival and functional outcomes in older head-injured individuals. J Trauma. 2011;71(4):815-9. 
24. Susman MDS, Sullivan T, Risucci D, Nealon P, Cuff S, Haider A, Benzil D. Traumatic brain injury in the elderly: increased mortality and worse functional outcome at discharge despite lower injury severity. J Trauma. 2002;53(2):219-23.

25. Wong GK, Tang BY, Yeung JH, et al. Traumatic intracerebral haemorrhage: is the CT pattern related to outcome? $\mathrm{Br} \mathrm{J}$ Neurosurg. 2009;23(6):601-5.

26. Ohm C, Mina A, Howells G, et al. Effects of Antiplatelet Agents on Outcomes for Elderly Patients With Traumatic Intracranial Hemorrhage. J Trauma: Inj Infect Crit Care. 2005;58(3):518-22.

27. Lin JW, Tsai SH, Tsai WC, et al. Survey of traumatic intracranial hemorrhage in Taiwan. Surg Neurol. 2006;66 Suppl 2:S20-5.

28. Jagnoor J, Keay L, Ganguli A, et al. Fall related injuries: A retrospective medical review study in North India. Injury. 2011.

29. Cameron PA, Rainer TH, Mak P. Motor Vehicle Deaths in Hong Kong: Opportunities for Improvement. J Trauma: Inj Infect Crit Care. 2004;56(4):890-3.

30. Ushewokunze S, Nannapaneni R, Gregson BA, et al. Elderly patients with severe head injury in coma from the outset-has anything changed? Br J Neurosurg. 2004;18(6):604-7.

31. Sinha VD, Gupta V, Singh DK, et al. Geriatric head injuriesExperience and expectations. Indian Journal of Neurotrauma. 2008;5(2):69-73.

32. Lavoie A, Ratte S, Clas D, et al. Preinjury warfarin use among elderly patients with closed head injuries in a trauma center. J Trauma: Inj Infect Crit Care. 2004;56(4):802-7.

33. Claudia C, Claudia R, Agostino O, et al. Minor head injury in warfarinized patients: indicators of risk for intracranial hemorrhage. $\mathrm{J}$ Trauma. 2011;70(4):906-9.

34. Franko J, Kish KJ, O'Connell BG, et al. Advanced age and preinjury warfarin anticoagulation increase the risk of mortality after head trauma. J Trauma. 2006;61(1):107-10.

35. Karni A, Holtzman R, Bass T, et al. Traumatic head injury in the anticoagulated elderly patient: a lethal combination. Am Surg. 2001;67(11):1098-100.

36. Cohen DB, Rinker C, Wilberger JE. Traumatic brain injury in anticoagulated patients. J Trauma. 2006;60(3):553-7.

37. Itshayek E, Rosenthal G, Fraifeld S, et al. Delayed posttraumatic acute subdural hematoma in elderly patients on anticoagulation. Neurosurgery. 2006;58(5):E851-6. discussion E-6.

38. Peck KA, Sise CB, Shackford SR, et al. Delayed intracranial hemorrhage after blunt trauma: are patients on preinjury anticoagulants and prescription antiplatelet agents at risk? J Trauma. 2011;71(6):1600-4.

39. Garber ST, Sivakumar W, Schmidt RH. Neurosurgical complications of direct thrombin inhibitors-catastrophic hemorrhage after mild traumatic brain injury in a patient receiving dabigatran. $\mathrm{J}$ Neurosurg. 2012

40. Wong DK, Lurie F, Wong LL. The effects of clopidogrel on elderly traumatic brain injured patients. J Trauma. 2008;65 (6):1303-8.

41. Downey DM, Monson B, Butler KL, et al. Does platelet administration affect mortality in elderly head-injured patients taking antiplatelet medications? Am Surg. 2009;75(11):1100-3.

42. •• Washington CW, Schuerer DJ, Grubb Jr RL. Platelet transfusion: an unnecessary risk for mild traumatic brain injury patients on antiplatelet therapy. J Trauma. 2011;71(2):358-63. This study suggested that platelet transfusion could be a futile effort to patients with mild TBI (GCS $\geq 13$ ) after studying 113 patients who were on antiplatelets while suffering from mild TBI. There was a trend of medical decline in patients who received platelet transfusion.

43. Fortuna GR, Mueller EW, James LE, et al. The impact of preinjury antiplatelet and anticoagulant pharmacotherapy on outcomes in elderly patients with hemorrhagic brain injury. Surgery. 2008;144 (4):598-603. discussion -5 .
44. Bachelani AM, Bautz JT, Sperry JL, et al. Assessment of platelet transfusion for reversal of aspirin after traumatic brain injury. Surgery. 2011;150(4):836-43.

45. Inaba K, Teixeira PG, David JS, et al. Beta-blockers in isolated blunt head injury. J Am Coll Surg. 2008;206(3):432-8.

46. $\mathrm{Wu} \mathrm{X,} \mathrm{Hu} \mathrm{J,} \mathrm{Zhuo} \mathrm{L,} \mathrm{et} \mathrm{al.} \mathrm{Epidemiology} \mathrm{of} \mathrm{traumatic} \mathrm{brain} \mathrm{injury}$ in eastern China, 2004: a prospective large case study. J Trauma. 2008;64(5):1313-9.

47. Jennett B, Teasdale G, Braakman R, et al. Predicting outcome in individual patients after severe head-injury. Lancet. 1976;1 (7968):1031-4.

48. Kilaru S, Garb J, Emhoff T, et al. Long-term functional status and mortality of elderly patients with severe closed head injuries. J Trauma. 1996;41(6):957-63.

49. Hukkelhoven CW, Steyerberg EW, Rampen AJ, et al. Patient age and outcome following severe traumatic brain injury: an analysis of 5600 patients. J Neurosurg. 2003;99(4):666-73.

50. Styrke J, Stalnacke BM, Sojka P, et al. Traumatic brain injuries in a well-defined population: epidemiological aspects and severity. J Neurotrauma. 2007;24(9):1425-36.

51. Nakamura N, Yamaura A, Shigemori M, et al. Final report of the Japan Neurotrauma Data Bank project 1998-2001: 1,002 cases of traumatic brain injury. Neurol Med Chir (Tokyo). 2006;46(12):567-74.

52. Yap SG, Chua KS. Rehabilitation outcomes in elderly patients with traumatic brain injury in Singapore. J Head Trauma Rehabil. 2008;23(3):158-63.

53. •• Wong GK, Graham CA, Ng E, et al. Neurological outcomes of neurosurgical operations for multiple trauma elderly patients in Hong Kong. J Emerg Trauma Shock. 2011;4(3):346-50. In this study, $32 \%$ of the elderly patients who underwent neurosurgical operations for traumatic brain injury attained favorable neurological outcomes (GOS 4-5) at 6 months.

54. Mohindra S, Mukherjee KK, Gupta R, et al. Continuation of poor surgical outcome after elderly brain injury. Surg Neurol. 2008;69 (5):474-7.

55. - Lau D, El-Sayed AM, Ziewacz JE, et al. Postoperative outcomes following closed head injury and craniotomy for evacuation of hematoma in patients older than 80 years. J Neurosurg. 2012;116 (1):234-45. In comparison with younger patients, TBI patients over 80 years of age showed no difference in 30-day mortality and can similarly return to preinjury functional baselines with adequate postoperative rehabilitation.

56. Plassman BL, Havlik RJ, Steffens DC, et al. Documented head injury in early adulthood and risk of Alzheimer's disease and other dementias. Neurology. 2000;55(8):1158-66.

57. Goldstein FC, Levin HS. Cognitive outcome after mild and moderate traumatic brain injury in older adults. J Clin Exp Neuropsychol. 2001;23(6):739-53.

58. Jellinger K. Traumatic brain injury as a risk factor for Alzheimer's disease. J Neurol Neurosurg Psychiatry. 2004;75(3):511-2.

59. Luukinen H, Viramo $P$, Herala M, et al. Fall-related brain injuries and the risk of dementia in elderly people: a population-based study. Eur J Neurol. 2005;12(2):86-92.

60. Helmes E, Ostbye T, Steenhuis RE. Incremental contribution of reported previous head injury to the prediction of diagnosis and cognitive functioning in older adults. Brain Inj. 2011;25(4):338-47.

61. Wong GK, Ngai K, Wong A, et al. Long-term cognitive dysfunction in patients with traumatic subarachnoid hemorrhage: prevalence and risk factors. Acta Neurochir (Wien). 2012;154(1):105-11. discussion 11.

62. McKee AC, Cantu RC, Nowinski CJ, et al. Chronic traumatic encephalopathy in athletes: progressive tauopathy after repetitive head injury. J Neuropathol Exp Neurol. 2009;68(7):709-35.

63. McKee AC, Gavett BE, Stern RA, et al. TDP-43 proteinopathy and motor neuron disease in chronic traumatic encephalopathy. J Neuropathol Exp Neurol. 2010;69(9):918-29. 
64. Rao V, Bertrand M, Rosenberg P, et al. Predictors of new-onset depression after mild traumatic brain injury. J Neuropsychiatry Clin Neurosci. 2010;22(1):100-4.

65. Rao V, Munro CA, Rosenberg P, et al. Neuroanatomical correlates of depression in post traumatic brain injury: preliminary results of a pilot study. J Neuropsychiatry Clin Neurosci. 2010;22 (2):231-5.

66. Rao V, Rosenberg P, Miles QS, et al. Neuropsychiatric symptoms in dementia patients with and without a history of traumatic brain injury. J Neuropsychiatry Clin Neurosci. 2010;22(2):166-72.

67. Onyszchuk G, He YY, Berman NE, et al. Detrimental effects of aging on outcome from traumatic brain injury: a behavioral, magnetic resonance imaging, and histological study in mice. J Neurotrauma. 2008;25(2):153-71.

68. Onyszchuk G, LeVine SM, Brooks WM, et al. Post-acute pathological changes in the thalamus and internal capsule in aged mice following controlled cortical impact injury: a magnetic resonance imaging, iron histochemical, and glial immunohistochemical study. Neurosci Lett. 2009;452(2):204-8.

69. Sandhir R, Berman NE. Age-dependent response of CCAAT/ enhancer binding proteins following traumatic brain injury in mice. Neurochem Int. 2010;56(1):188-93.

70. Colak T, Cine N, Bamac B, et al. Microarray-based gene expression analysis of an animal model for closed head injury. Injury. 2012.

71. Mehan ND, Strauss KI. Combined age- and trauma-related proteomic changes in rat neocortex: a basis for brain vulnerability. Neurobiol Aging. 2011.

72. Swan AA, Chandrashekar R, Beare J, et al. Preclinical efficacy testing in middle-aged rats: nicotinamide, a novel neuroprotectant, demonstrates diminished preclinical efficacy after controlled cortical impact. J Neurotrauma. 2011;28(3):431-40.

73. Marklund N, Morales D, Clausen F, et al. Functional outcome is impaired following traumatic brain injury in aging Nogo-A/Bdeficient mice. Neuroscience. 2009;163(2):540-51.

74. Harting MT, Baumgartner JE, Worth LL, et al. Cell therapies for traumatic brain injury. Neurosurg Focus. 2008;24(3-4):E18.

75. Fortier LA. Stem cells: classifications, controversies, and clinical applications. Vet Surg. 2005;34(5):415-23.
76. Schouten JW, Fulp CT, Royo NC, et al. A review and rationale for the use of cellular transplantation as a therapeutic strategy for traumatic brain injury. J Neurotrauma. 2004;21(11):1501-38.

77. Bianco P, Robey PG, Simmons PJ. Mesenchymal stem cells: revisiting history, concepts, and assays. Cell Stem Cell. 2008;2(4):313-9.

78. Mahmood A, Lu D, Lu M, et al. Treatment of traumatic brain injury in adult rats with intravenous administration of human bone marrow stromal cells. Neurosurgery. 2003;53(3):697-702. discussion -3

79. Harting MT, Jimenez F, Xue H, et al. Intravenous mesenchymal stem cell therapy for traumatic brain injury. J Neurosurg. 2009;110 (6):1189-97.

80. Bhang SH, Lee YE, Cho SW, et al. Basic fibroblast growth factor promotes bone marrow stromal cell transplantation-mediated neural regeneration in traumatic brain injury. Biochem Biophys Res Commun. 2007;359(1):40-5.

81. Richardson RM, Singh A, Sun D, et al. Stem cell biology in traumatic brain injury: effects of injury and strategies for repair. J Neurosurg. 2010;112(5):1125-38.

82. Delcroix GJ, Schiller PC, Benoit JP, et al. Adult cell therapy for brain neuronal damages and the role of tissue engineering. Biomaterials. 2010;31(8):2105-20.

83. Cox Jr CS, Baumgartner JE, Harting MT, et al. Autologous bone marrow mononuclear cell therapy for severe traumatic brain injury in children. Neurosurgery. 2011;68(3):588-600.

84. Joyce N, Annett G, Wirthlin L, et al. Mesenchymal stem cells for the treatment of neurodegenerative disease. Regen Med. 2010;5 (6):933-46.

85. Gao J, Dennis JE, Muzic RF, et al. The dynamic in vivo distribution of bone marrow-derived mesenchymal stem cells after infusion. Cells Tissues Organs. 2001;169(1):12-20.

86. Lam PK, Ng CF, To KF, et al. Topical application of mesenchymal stem cells to somatic organs-a preliminary report. Transplantation. 2011;92(2):e9-e11.

87. • Lam PK, Lo AWI, Wang KKW. Transplantation of mesenchymal stem cells to the brain by topical application in an experimental brain injury. J Clin Neuro 2012, In press. The authors note that a novel research on topical application of mesenchymal stem cells could prove feasible and applicable after traumatic brain injury in mouse models. 